\title{
Glutamate Receptors in Nucleus Accumbens Mediate Regionally Selective Increases in Cortical Acetylcholine Release
}

\author{
AMY ZMAROWSKI, ${ }^{1}$ MARTIN SARTER, ${ }^{2}$ AND JOHN P. BRUNO ${ }^{1,3 *}$ \\ ${ }^{1}$ Department of Psychology, The Ohio State University, Columbus, Ohio \\ ${ }^{2}$ Department of Psychology, University of Michigan, Ann Arbor, Michigan \\ ${ }^{3}$ Department of Neuroscience, The Ohio State University, Columbus, Ohio
}

\begin{abstract}
KEY WORDS acetylcholine; attention; basal forebrain; glutamate; nucleus accumbens; prefrontal cortex; parietal cortex
\end{abstract}

\begin{abstract}
The basal forebrain cortical cholinergic system (BFCS) is critical for the regulation of attentional information processing. BFCS activity is regulated by several cortical and subcortical structures, including the nucleus accumbens (NAC) and prefrontal cortex (PFC). GABAergic projection neurons from NAC to basal forebrain are modulated by Glu receptors within NAC. We previously reported that intraNAC perfusions of NMDA or its antagonist CPP stimulate ACh release in PFC. In this experiment we determined whether this trans-synaptic modulation of cortical ACh release is evident in multi-sensory associational areas like the posterior parietal cortex (PPC). Artificial cerebrospinal fluid (aCSF, control), NMDA (250 or $400 \mu \mathrm{M})$, or CPP (200 or $400 \mu \mathrm{M}$ ) were perfused into the NAC shell and ACh was measured in the ipsilateral PPC. Amphetamine $(2.0 \mathrm{mg} / \mathrm{kg}$, i.p), was systemically administered as a positive control in a fourth session, since it also stimulates cortical ACh release but via mechanisms known to not necessitate transmission within the NAC. Neither NMDA nor CPP increased ACh efflux in the PPC, yet both drugs increased ACh release in PFC, suggesting that NMDA receptor modulation in the NAC increases $\mathrm{ACh}$ in the cortex in a regionally-specific manner. Systemic amphetamine administration significantly increased (100-200\%) ACh in the PPC, suggesting that levels of ACh in the PPC can be increased following certain pharmacological manipulations. The cortical region-specific modulation of ACh by NAC may underlie the linkage of motivational information with top-down controls of attention as well as guide appropriate motor output following exposure to salient and behaviorally relevant stimuli. Synapse 61:115-123, 2007. $\odot 2006$ Wiley-Liss, Inc.
\end{abstract}

\section{INTRODUCTION}

The cholinergic projections from the basal forebrain project to all areas and layers of the neocortex (Mechawar et al., 2000). This basal forebrain cortical cholinergic system (BFCS) has been demonstrated to be critical for normal attentional processing (Dalley et al., 2004; Mizra and Stolerman, 1998; Muir et al., 1995; Sarter et al., 2005a). Furthermore, dysregulations in the functioning of this system have been postulated to contribute to the cognitive deficits accompanying several neuropsychiatric disorders (Isacson et al., 2002; Sarter and Bruno, 1997; Sarter et al., 2005b; Tandon et al., 1991). A two-tiered model has been proposed, suggesting that attentional processing during sensory orienting is achieved by two separate but interacting circuits: a dorsal and a ventral attention system. The ventral system mediates signal-based or stimulus-driven aspects of attention and its operations are referred to as bottom-up processing. The dorsal system involves modulation of attentional function through knowledge-based or executive control and its operations are referred to as top-down processing (Corbetta and Shulman, 2002;

\footnotetext{
Contract grant sponsor: NIH; Contract grant numbers: MH057436, MH063114, NS 37,026, and KO2MH01072.

*Correspondence to: Dr. John P. Bruno, Dept. of Psychology, 57 Psychology Building, The Ohio State University, Columbus, OH 43210.

E-mail: bruno.1@osu.edu

Received 16 August 2006; Accepted 25 September 2006

DOI 10.1002/syn.20354

Published online in Wiley InterScience (www.interscience.wiley.com).
} 
Fox et al., 2006; Posner and Petersen, 1990; Sarter et al., 2001, 2005a).

The prefrontal cortex (PFC) is a central component of the dorsal attentional system, participating in the regulation of attentional processes particularly under conditions when the salience of the signal is low, irrelevant information must be filtered, or biases of stimulus selection are warranted (Posner and Petersen, 1990; Sarter et al., 2001). The PFC contributes topdown control over attentional processing through multi-synaptic projections to other cortical regions (such as posterior parietal cortex, PPC) or corticofugal projections to basal forebrain (Nelson et al., 2005; Zaborszky and Duque, 2000). An additional circuit contributing to the linking of motivational states and attentional priorities is the link between PFC and the nucleus accumbens (NAC; Pinto and Sesack, 2000; Reynolds and Zahm, 2005). Projections from the shell region of the NAC to cholinergic neurons of the basal forebrain (Zaborszky and Cullinan, 1992) would then influence projections of the BFCS (Moore et al., 1999; Neigh et al., 2004).

We previously reported, using dual probe microdialysis experimental designs, that intra-NAC perfusions of NMDA receptor agonists and antagonists into the shell region of the NAC result in increased $\mathrm{ACh}$ release in PFC in awake yet resting rats (Neigh-McCandless et al., 2002; Zmarowski et al., 2005). We postulated that changes in NMDA receptor activity in NAC that serve to modulate cholinergic input to PFC may, in part, reflect a neuronal circuit that participates in the topdown controls of attentional processing. As such, we would expect that these NMDA-receptor-induced changes in cortical ACh release are restricted to the prefrontal region and do not, under conditions in which the animal is at rest, extend to other cortical regions participating in attentional processing such as the PPC. In the present experiment, NMDA or the NMDA antagonist CPP were perfused into the NAC shell and $\mathrm{ACh}$ release was determined in PPC. As a positive control for the ability to stimulate $\mathrm{ACh}$ release in $\mathrm{PPC}$, animals also received a systemic injection of amphetamine. We have previously shown that amphetamineinduced $\mathrm{ACh}$ release does not involve transmission within NAC (Arnold et al., 2000).

\section{MATERIALS AND METHODS Subjects}

Male Wistar rats (Charles River Labs, Wilmington, MA) weighing between 300 and $400 \mathrm{~g}$ were utilized for all studies. Animals were maintained on a 12:12 h light:dark cycle (lights on: 0600) in a temperatureand humidity-controlled room. Animals were individually housed in plastic cages lined with corn cob bedding (Harlan Teklad, Madison, WI) and had access to food and water ad libitum. All procedures involving animals were approved by The Ohio State University Institutional Animal Care and Use Committee in accordance with the NIH Guide for the Care and Use of Laboratory Animals.

Three days prior to surgery, animals were acclimated to the microdialysis testing environment in clear plastic bowls $(35 \times 38 \mathrm{~cm}$ (height $\times$ diameter $)$; CMA, Stockholm, Sweden) lined with corn cob bedding. Animals remained in the bowls for a minimum of $4 \mathrm{~h}$ /day, and returned to their home cages at the end of each acclimation period.

\section{Surgery}

Following 3 days of acclimation, animals were anesthetized using isoflurane gas $\left(2 \%, 0.6 \mathrm{~L} / \mathrm{min}, \mathrm{O}_{2}\right.$ delivery) and unilaterally implanted with microdialysis guide cannuale (0.38 mm o.d.; Sci Pro, Sanborn, NY) into the nucleus accumbens shell (NAC; in $\mathrm{mm}$ from bregma: $\mathrm{AP}+1.3, \mathrm{ML} \pm 1.0, \mathrm{DV}-5.8$ ), and the ipsilateral posterior parietal cortex (PPC; in $\mathrm{mm}$ from bregma: $\mathrm{AP}-4.4, \mathrm{ML} \pm 1.5, \mathrm{DV}-0.5$, with the tip of the guide oriented at $45^{\circ}$ laterally). Cannuale were inserted with dummy stylets to prevent occlusion. All guide cannulae were fixed using dental cement and three stainless steel skull screws. The surgical site was swabbed with a topical antibiotic ointment (lidocane, 5\%), and animals received a prophylactic dose of the antibiotic amoxicillin (100 mg/kg) subcutaneously. Animals were allowed to recover for 3 days following surgery while being further acclimated daily to the microdialysis testing environment.

\section{Experimental procedures}

Animals ( $n=6$ ) were tested four times, with a different pharmacological manipulation (vehicle-aCSF, $250 \mu \mathrm{M}$ NMDA or $200 \mu \mathrm{M}$ CPP), administered, in counterbalanced order, every other day. As a positive control, last dialysis session consisted of administration of amphetamine (2.0 mg/kg, i.p.), a manipulation known to increase cortical ACh via mechanisms that do not necessitate changes in NAC transmission (Arnold et al., 2000). Following the 3-h wash-out period, four baseline samples were collected; 15 min collection intervals were observed with all time points. Following the four baseline collections, the syringe was switched from aCSF to one containing aCSF + drug (250 $\mu \mathrm{M}$ NMDA, $200 \mathrm{CPP}$, or aCSF vehicle). Following a 15-min wash-out, four additional collections were taken before switching the syringe back to one containing only aCSF. This perfusion lasted a total of $60 \mathrm{~min}$, including an initial 15-min wash-out period. Following the last collection, probes were removed and stylets were reinserted before returning animals to their home cages. For the last session, dialysis was conducted as described above through the 3-h washout period and the four baseline collections. After the 
completion of baseline collections, animals received amphetamine $(2.0 \mathrm{mg} / \mathrm{kg}$, i.p.). A total of eight drug collections (15 min each) were taken immediately following the injection; no 15-min wash-out period was observed. Following the last collection, probes were removed and stylets were reinserted as described above.

The effects of higher concentrations of these drugs were assessed in a separate group of animals $(n=6)$, to test for any concentration-dependent changes in ACh efflux. Sessions were conducted in the exact same manner as described above, except the original concentrations of the NMDA receptor ligands were replaced with $400 \mu \mathrm{M}$ NMDA, and $400 \mu \mathrm{M}$ CPP.

\section{General microdialysis procedures}

Microdialysis sessions were conducted using repeated perfusions, with each animal receiving four different pharmacological manipulations, one every other day. This repeated testing paradigm has the advantage of decreasing variability among treatment conditions because each subject serves as its own control. Furthermore, it allows for paradigms such as dose-response analyses, as well as agonist-antagonist interactions to be studied in the same animal. The procedure has been repeatedly validated by demonstrating that basal cortical ACh efflux does not significantly change over repeated dialysis sessions, and that the effects of behavioral, pharmacological, or sensory manipulations on ACh levels do not interact with dialysis sessions (Bruno et al., 1999; Nelson et al., 2000).

On the fourth day following surgery, animals were brought to the testing environment and allowed to acclimate for $30 \mathrm{~min}$ prior to the insertion of microdialysis probes. Following the $30 \mathrm{~min}$ acclimation period, stylets were removed and probes (Sci Pro, $0.2 \mathrm{~mm}$ o.d., $3.0 \mathrm{~mm}$ membrane tip for PPC, $0.2 \mathrm{~mm}$ o.d., $2.0 \mathrm{~mm}$ membrane tip for $\mathrm{NAC}$ ) were inserted into each guide.

Probes were continuously perfused with artificial cerebral spinal fluid (aCSF; containing in $\mathrm{mM}: \mathrm{NaCl}$ 166.5, $\mathrm{NaHCO}_{3} 27.5, \mathrm{KCL} 2.4, \mathrm{CaCl}_{2} 1.2, \mathrm{Na}_{2} \mathrm{SO}_{4}$ 0.5, $\mathrm{KH}_{2} \mathrm{PO}_{4} 0.5$, glucose $1.0, \mathrm{pH} 7.1$ ) at a flow rate of $1.25 \mathrm{\mu l} / \mathrm{min}$. No acetylcholinesterase inhibitor was utilized in any experiment. A 3-h wash-out period was observed after probe insertion to allow ACh efflux to reach a stable baseline that was maximally sensitive to TTX before beginning collections (Moore et al., 1992).

\section{HPLC analysis}

Dialysis samples were stored at $-80^{\circ} \mathrm{C}$ until analyzed using high performance liquid chromatography (HPLC) with electrochemical detection. A volume of
$15 \mu \mathrm{l}$ of each sample was injected by autosampler (ESA, Chelmsford, MA). ACh and choline were separated by an UniJet microbore analytical column (BAS; $1 \times 50 \mathrm{~mm}^{2}$ ) using a sodium phosphate mobile phase $\left(35 \mathrm{mM} \mathrm{Na} \mathrm{NPO}_{4}, 484 \mu \mathrm{M}\right.$ EDTA, $0.005 \%$ microbicide reagent ProClin, $\mathrm{pH}=8.5$, flow rate $=$ $0.15 \mathrm{ml} / \mathrm{min}$ ). A precolumn immobilized enzyme reactor (IMER; BAS) was used to hydrolyze choline, and a postcolumn IMER containing acetylcholinesterase and choline oxidase was used to break down ACh into $\mathrm{H}_{2} \mathrm{O}_{2}$ (Potter et al., 1983), and quantified using a peroxidase-wired ceramic glassy carbon electrode (Model no. 5041 microdialysis analytical cell, ESA).

\section{Histology}

Following the final microdialysis session, animals were given an overdose of sodium pentobarbital and transcardially perfused with $0.9 \%$ heparinized saline followed by $10 \%$ formalin. Brains were removed and stored in $10 \%$ formalin for at least $24 \mathrm{~h}$, and were then transferred to a $30 \%$ sucrose solution for 3 days. Brains were sectioned $(50 \mu \mathrm{M})$ using a cryostat, mounted on gelatin-coated slides, stained using Cresyl Violet, and examined under a light microscope. Subjects whose probes were located outside any of the targeted regions were excluded from further analysis.

\section{Data analysis}

The effects of individual drug treatments on PPC release were analyzed using separate ANOVAs. Furthermore, to illustrate the contrast between the present results on PPC ACh release and prior evidence on PFC release, the prior data are reproduced in the figures. These regional comparisons are justified by the fact that the studies conducted in the present experiment and our previous reports utilized identical microdialysis and testing methods.

Changes in basal ACh efflux (fmol/15 $\mu \mathrm{l}$ ) across sessions and treatment groups were analyzed using oneway repeated measures analysis of variance (ANOVAs). In the absence of any session or group effects, basal efflux was then defined as the mean of the four baseline collections, and subsequent data were expressed as percent change from that mean baseline. Overall statistical analysis of drug effects was conducted using a two-way, within-subjects ANOVA with drug GROUP and TIME as within-subjects measures. In some cases, one-way ANOVAs were conducted for each drug with TIME as a repeated, within-subject measure $(\alpha=0.05)$. The Huynh-Feldt correction was utilized to reduce Type I errors associated with repeated measures ANOVAs (Vasey and Thayer, 1987). Exact $P$-values were reported (Greenwald et al., 1996). All statistical tests were preformed using SPSS for windows (V14.0, Chicago, IL). 

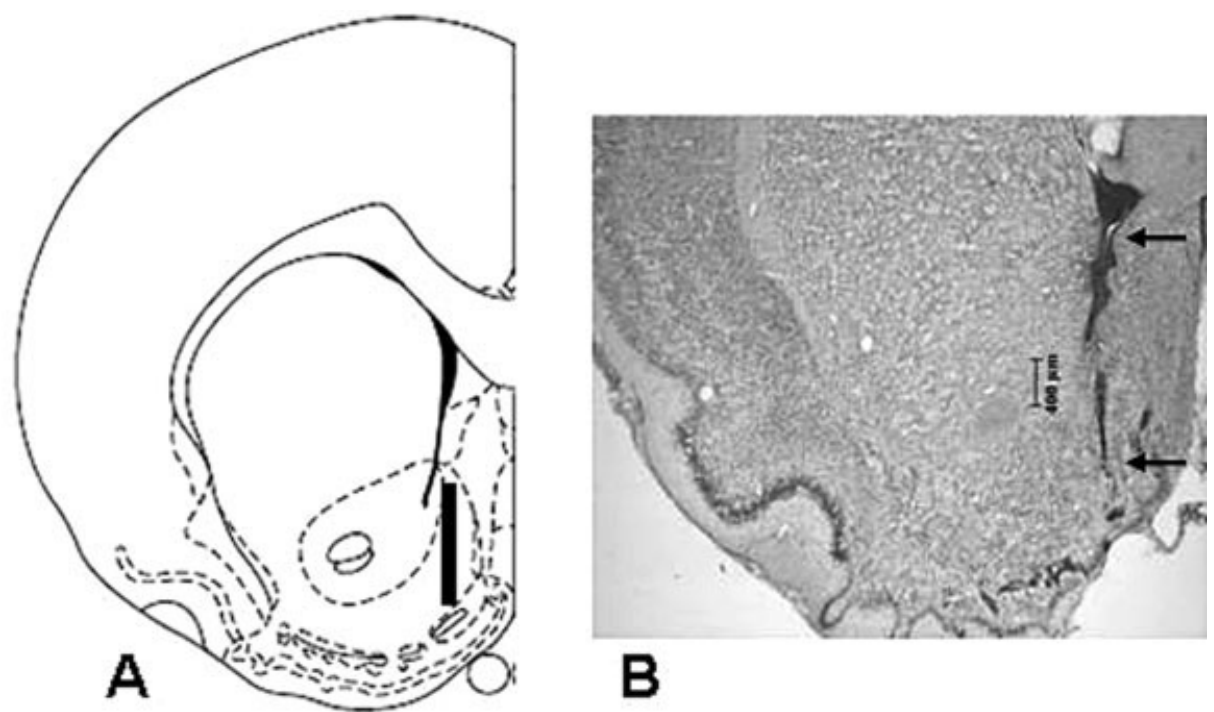

B
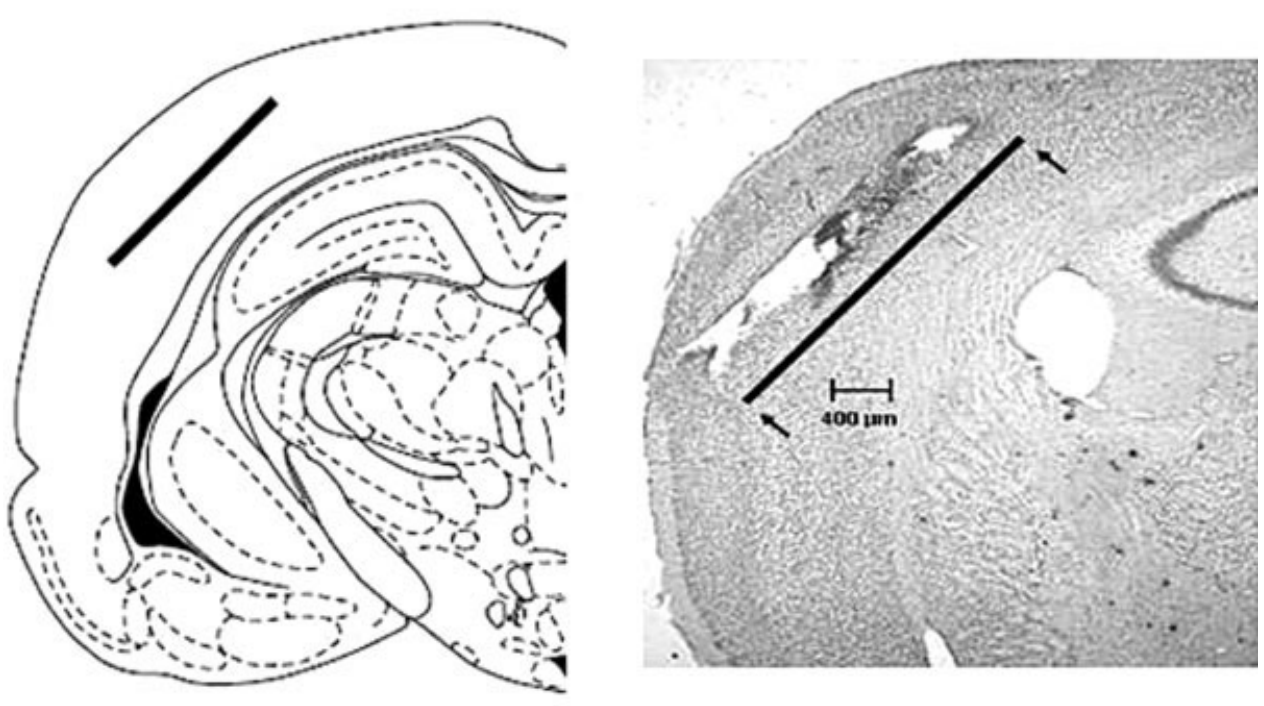

C

Fig. 1. A: depicts a schematic of a NAC placement. Guides were implanted so that when probes were inserted ( $2 \mathrm{~mm}$ active tip), the membrane tip was located in the shell region of the NAC. B: is a photomicrograph of a representative NAC shell placement illustrated in Panel A. The area between the arrows represents the active membrane tip $(2.0 \mathrm{~mm})$. C: depicts a schematic representation

\section{RESULTS \\ Microdialysis probe placements}

Figure 1 shows representative placements of microdialysis probes in the shell region of the NAC (Fig. 1A,B) and the ipsilateral PPC (Fig. 1C,D). Animals whose probe placements fell outside the NAC shell or PPC were excluded from further analysis.

\section{Basal levels of ACh efflux in PPC}

Basal levels of ACh efflux were stable over the four dialysis SESSIONs $\left(F_{3,15}=2.227, P=0.127\right)$, and

of a PPC placement. Guides were implanted so that when probes were inserted, the membrane tip was located in the PPC with the tip of the guide oriented at $45^{\circ}$ laterally. D: is a photomicrograph that is representative of the PPC placement illustrated in Panel C. The area between the arrows represents the active membrane tip $(3.0 \mathrm{~mm})$.

across the four treatment GROUPs $\left(F_{3,15}=1.327\right.$, $P=0.305$ ). Basal levels of ACh (mean \pm SEM, fmol/ $15 \mu \mathrm{l})$ were $8.1 \pm 2.5,9.8 \pm 1.9,7.0 \pm 1.5$, and $5.0 \pm$ 1.7 for aCSF, $250 \mu \mathrm{M}$ NMDA, $200 \mu \mathrm{M}$ CPP, and amphetamine sessions, respectively. Given that basal levels of ACh efflux did not differ over session or group, all subsequent values were expressed and analyzed as a percent change from session baseline.

\section{Regional effects of NMDA}

Figure 2 illustrates that the effects of NMDA on ACh efflux differed markedly between PFC and PPC. 


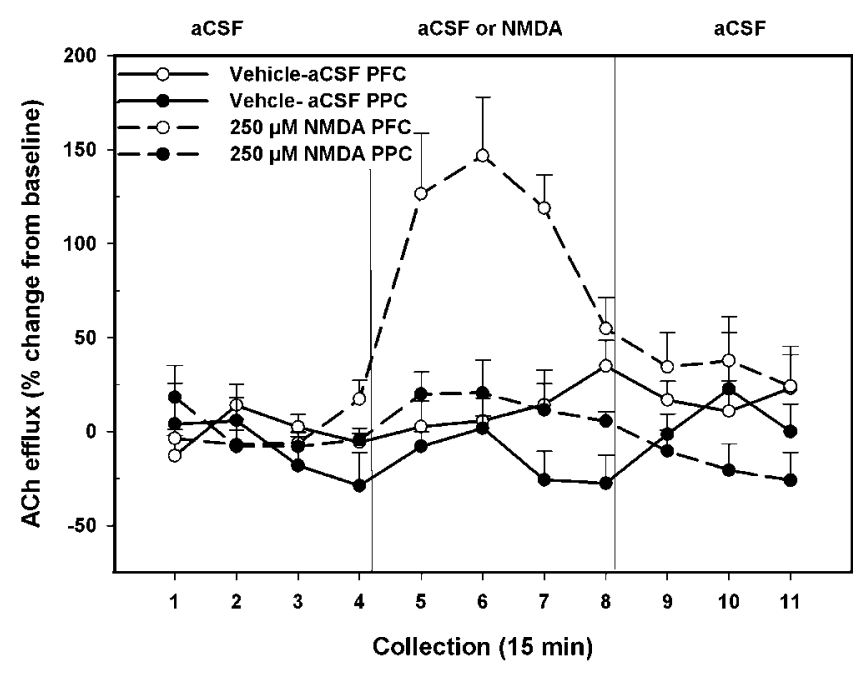

Fig. 2. Comparison between ACh efflux measured from the $\mathrm{mPFC}$ and PPC after intra-NAC administration of NMDA. Mean $( \pm$ SEM) ACh efflux in the PPC $(n=6)$ and $\operatorname{mPFC}(n=9$; data collected using identical microdialysis methods and previously reported in Zmarowski et al., 2005). In both cases, rats received, in counterbalanced order, vehicle (aCSF) or NMDA alone $(250 \mu \mathrm{M})$ into the NAC shell during separate dialysis sessions. Following baseline collections (Collections 1-4), vehicle or NMDA was administered for $60 \mathrm{~min}$ (Collections 5-8). Upon conclusion of the $60 \mathrm{~min}$ perfusion, aCSF alone was perfused for 30 min until the end of the dialysis period (Collections 9-11). NMDA increased ACh efflux above vehicle session in the mPFC (Zmarowski et al., 2005). However, NMDA did not significantly increase ACh above vehicle levels when measured from the PPC.

As reported previously, intra-NAC perfusions of NMDA $(250 \mu \mathrm{M})$ stimulated ACh efflux, relative to the aCSF control session, in PFC (Zmarowski et al., 2005). In contrast, similar infusions of NMDA did not stimulate ACh efflux, relative to the aCSF control session, in $\mathrm{PPC}\left(F_{1,5}=3.138, P=0.137\right)$.

\section{Regional effects of CPP}

Figure 3 illustrates that the effects of intra-NAC administration of the NMDA antagonist CPP on ACh release differed in $\mathrm{PFC}$ and $\mathrm{PPC}$. We previously reported that intra-NAC perfusions of CPP $(200 \mu \mathrm{M})$ produced a robust and long-lasting stimulation of ACh efflux, relative to the aCSF control session, in PFC (Neigh-McCandless et al., 2002). In contrast, similar infusions of CPP did not stimulate ACh efflux, relative to the aCSF control session, in $\operatorname{PPC}\left(F_{1,5}=\right.$ $3.31, P=0.128)$.

\section{Effects of higher concentrations of drugs on ACh release in PPC}

A separate group of animals was tested with a higher concentration of either NMDA or CPP to determine if the cortical differences reflected a rightward shift in the dose response curve for ACh release in PPC. Basal levels of efflux were stable over the four dialysis SESSIONs $\left(F_{3,15}=2.962, P=0.116\right)$ as

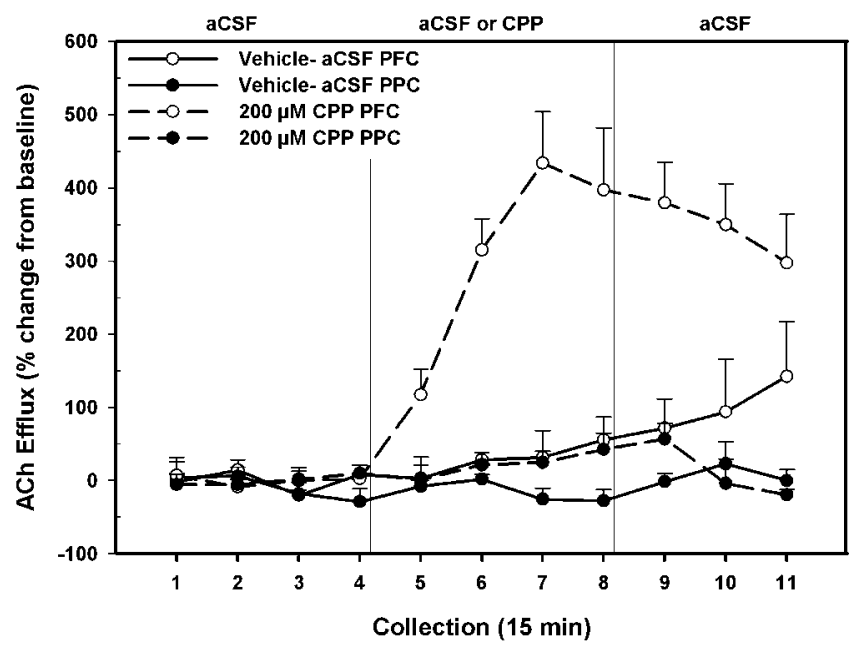

Fig. 3. Comparison between ACh efflux measured from the mPFC and PPC after intra-NAC administration of the NMDA antagonist. Mean $( \pm$ SEM) ACh efflux in the PPC $(n=6)$ and mPFC ( $n=9$; data collected using identical microdialysis methods and previously reported in Neigh et al., 2004). In both cases, rats received, in counterbalanced order, vehicle (aCSF) or CPP alone $(200 \mu \mathrm{M})$ into the NAC shell during separate dialysis sessions. Following baseline collections (Collections 1-4), vehicle or CPP was administered for $60 \mathrm{~min}$ (Collections 5-8). Upon conclusion of the $60 \mathrm{~min}$ perfusion, aCSF alone was perfused for $30 \mathrm{~min}$ until the end of the dialysis period (Collections 9-11). CPP increased ACh efflux above vehicle session in the mPFC (Neigh et al., 2004). However, CPP did not significantly increase $\mathrm{ACh}$ above vehicle levels when measured from the PPC.

revealed by one-way ANOVAs. Basal levels of ACh (mean $\pm \mathrm{SEM}, \mathrm{fmol} / 15 \mu \mathrm{l}$ ) were $6.0 \pm 1.1,8.9 \pm 2.6$, $8.1 \pm 1.6$, and $2.7 \pm 0.7$ for aCSF, $400 \mu \mathrm{M}$ NMDA, $400 \mu \mathrm{M} \mathrm{CPP}$ and amphetamine sessions, respectively. Significant differences in basal efflux were seen when compared across the four treatment GROUPs $\left(F_{3,15}=\right.$ 3.912, $P=0.032$ ). Pair-wise comparisons revealed that this effect was due solely to differences between basal levels for $400 \mu \mathrm{M}$ CPP and amphetamine sessions. However, given the basal levels were stable across dialysis sessions, and drug treatments were counterbalanced, it is not likely these differences in baseline led to such a systematic treatment effect as described below. Therefore, subsequent analyses were conducted and reported as percent change from baseline.

Figure 4 illustrates that the drug treatments led to differential effects on cortical ACh efflux (GROUP, $\left.F_{3,12}=11.229, P=0.015\right)$. These effects varied across collection interval (TIME, $F_{8,32}=3.894, P=$ 0.003 ; GROUP $\times$ TIME, $\left.F_{24,96}=3.204, P<0.001\right)$. A series of smaller, 2-way ANOVAs were conducted to look at differences between pairs of treatment groups. As was the case with the lower concentration of NMDA (Fig. 2), administration of $400 \mu \mathrm{M}$ NMDA did not increase ACh above aCSF vehicle in the PPC $\left(F_{1,4}=0.084, P=0.786\right)$. As described for the lower concentration of CPP (Fig. 3), perfusion of $400 \mu \mathrm{M}$ 


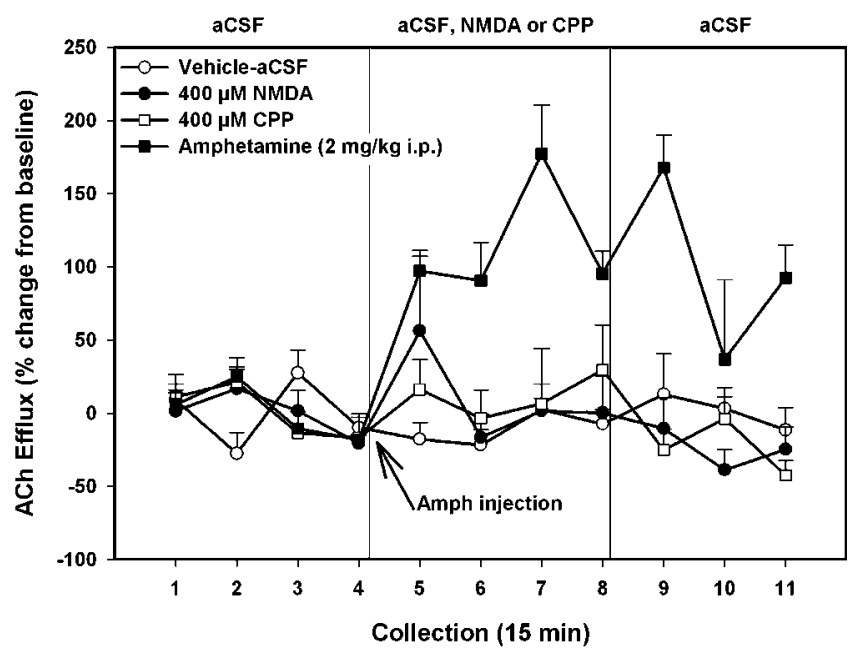

Fig. 4. Mean ( \pm SEM) ACh efflux in the PPC $(n=6)$ of animals receiving, in counterbalanced order, vehicle (aCSF), higher concentration of NMDA $(400 \mu \mathrm{M})$, or higher concentration of CPP $(400 \mu \mathrm{M})$ into the NAC shell during three separate dialysis sessions. Systemic amphetamine (2 mg/kg, i.p.) was administered as a fourth dialysis session. Following baseline collections (Collections 1-4), vehicle, NMDA, or CPP was administered for 60 min (Collections 5-8). Upon conclusion of the 60 min perfusion, aCSF alone was perfused for 30 min until the end of the dialysis period (Collections 9-11). Amphetamine was administered after four baseline collections in a fourth session, and ACh was collected for seven subsequent collections (Collections 5-11). Neither the higher concentration of NMDA or of CPP increased ACh efflux above vehicle session in the PPC. However, systemic administration significantly increased $\mathrm{ACh}$ above baseline.

CPP also failed to increase ACh in the PPC above the aCSF session $\left(F_{1,5}=0.14, P=0.91\right)$.

\section{Comparable effects of amphetamine in the two cortical regions}

In contrast to the effects of intra-NAC perfusions of NMDA or CPP, systemic administration of amphetamine $(2.0 \mathrm{mg} / \mathrm{kg}$, i.p.) stimulated $\mathrm{ACh}$ efflux in both PFC and PPC (Fig. 5). We have previously reported that amphetamine stimulates $\mathrm{ACh}$ release in $\mathrm{PFC}$ (Nelson et al., 2000) and those data are reproduced in Figure 5 to highlight the similarity in the drug response in the two regions of cortex. Amphetamine markedly stimulated $\mathrm{ACh}$ release in PPC relative to aCSF (GROUP, $F_{1,5}=10.195, P=0.024$; TIME, $F_{10,50}=3.862, P=0.048 ;$ GROUP $\times$ TIME, $F_{10,50}=$ 5.188, $P=0.007$ ) in the same animals that were unaffected by NMDA (Fig. 2) or CPP (Fig. 3). ACh efflux was significantly higher than aCSF within the first 15 min following systemic injection (Collection 2 in Fig. $\left.5, t_{2}=-2.94, P=0.016\right)$. The magnitude of the stimulated ACh efflux and its duration were comparable between the two cortical regions.

The ability of amphetamine to stimulate ACh release in PPC was also replicated in the group of animals that received the higher concentrations of the NMDA ligands (Fig. 4). ACh efflux was higher following amphetamine $(2.0 \mathrm{mg} / \mathrm{kg}$, i.p.) than in aCSF

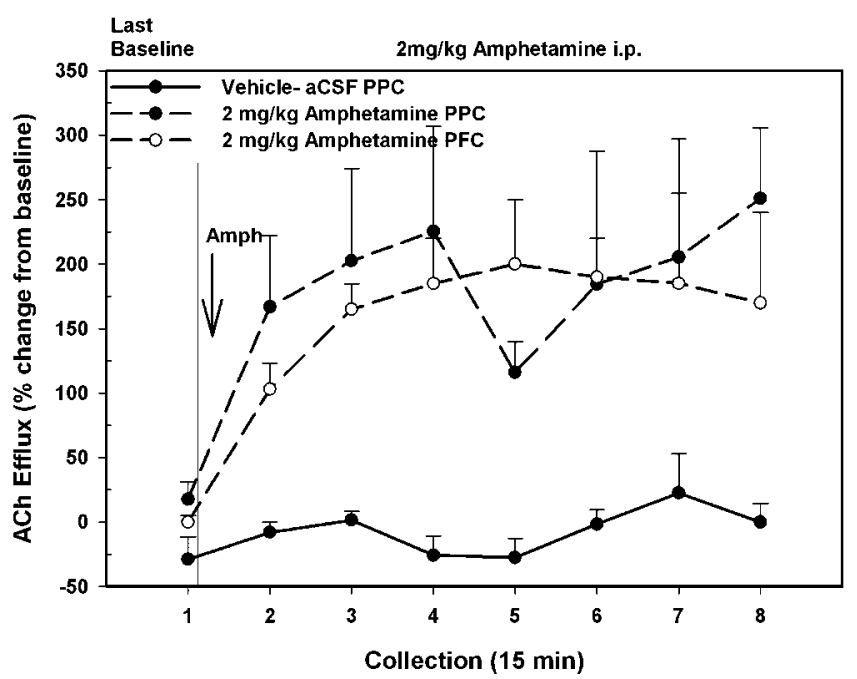

Fig. 5. Mean ( \pm SEM) ACh efflux in the $\operatorname{mPFC}(n=8$; data taken from Nelson et al., 2000, using identical microdialysis methods, for comparison purposes) and PPC $(n=6)$ of animals receiving amphetamine $(2 \mathrm{mg} / \mathrm{kg}$, i.p). Following $4 \mathrm{~h}$ of baseline collection, amphetamine was systemically administered and collected for eight subsequent collections. Only the last baseline and first seven collections are represented for comparison purposes with Nelson et al., 2000. Administration of amphetamine significantly increased ACh levels in PPC when compared to vehicle session alone. Moreover, ACh efflux in PPC following systemic amphetamine is comparable to levels measured in $\mathrm{mPFC}$.

controls (GROUP, $F_{1,5}=49.459, P=0.001$; TIME, $F_{8,40}=9.929, P<0.0001 ;$ GROUP $\times$ TIME, $F_{8,40}=$ 11.532, $P<0.0001)$.

\section{DISCUSSION}

The results of these experiments demonstrate that changes in NMDA receptor activity within the NAC are not sufficient to stimulate $\mathrm{ACh}$ release in PPC. The inability of intra-NAC perfusions of NMDA or its antagonist $\mathrm{CPP}$ to stimulate $\mathrm{ACh}$ release in $\mathrm{PPC}$ stands in contrast with previous reports demonstrating that these same perfusions markedly increase $\mathrm{ACh}$ release in another cortical region, the PFC (Neigh-McCandless et al., 2002; Zmarowski et al., 2005). Furthermore, ACh release in PPC can clearly be enhanced following a pharmacological treatment (i.e. amphetamine) that does not necessitate changes in NAC transmission. The discussion below addresses several interpretational issues regarding these results, speculates on the functional implications of this regional cortical selectivity of NAC modulation, and presents a hypothesis concerning this regional difference in the regulation of $\mathrm{ACh}$ release.

Intra-NAC perfusions of NMDA or CPP resulted in a marked stimulation of ACh release in $\mathrm{PFC}$ but neither drug led to significant changes in PPC. This regional selectivity of NAC modulation of cortical ACh release cannot be attributed to methodological differences between the current study and our previous 
reports (Neigh-McCandless et al., 2002; Zmarowski et al., 2005). The methods and procedures in these studies were identical, including the coordinates used for the intra-NAC perfusions. The inability to stimulate ACh release in PPC was also not due to a shift in the dose-response curve for NMDA receptor modulation of the parietal region as doubling the concentrations of either NMDA or CPP was still without effect. Finally, this regional difference does not reflect a general lack of dynamic regulation of ACh release within PPC. Systemic administration of amphetamine produced a long-lasting increase in ACh release in PPC in the same animals in which the lack of effect of intra-NAC NMDA receptor ligands was documented. Furthermore, we previously reported stimulation of ACh release in parietal cortex following several behavioral (Himmelheber et al., 1998, 2001; Kozak et al., 2006) and pharmacological treatments (Fadel et al., 1999; Moore et al., 1992, 1995). Thus, it would appear that the observed differences between ACh release in $\mathrm{PFC}$ and $\mathrm{PPC}$ were specific to the intraNAC perfusion of the NMDA agonist and antagonist.

Recent reports from other laboratories have also suggested regional differences in the regulation of cortical ACh release. Regionally specific activation of $\mathrm{ACh}$ release has been demonstrated in visual and somatosensory following presentation of either visual or somatosensory cortices stimuli (Fournier et al., 2004). Visual stimulation was also not associated with ACh release in prefrontal cortex (Laplante et al., 2005). Topographical projections from basal forebrain to sensory cortices may provide an anatomical basis for such modality-specific activation (Zaborszky, 2002; Zaborszky et al., 1999, 2005) although regulation of cortical ACh release by cortico-cortical projections to the terminal regions may also contribute to regional differences in ACh release.

Systemic administration of amphetamine differed from the NMDA ligands in that it was effective in stimulating ACh release in both PFC and PPC. The role of the NAC in the mediation of cortical ACh release following local NMDA or CPP perfusions vs. systemic amphetamine is different. Previous research has demonstrated that transmission within the NAC is not a critical feature of amphetamine-stimulated ACh release. Direct, intra-NAC perfusions of amphetamine were not sufficient to increase cortical ACh release. Moreover, intra-NAC perfusion of D1- or D2like antagonists did not attenuate the ability of systemic amphetamine to stimulate cortical ACh release (Arnold et al., 2000). The broad, distributed neuronal system mediating the effects of systemic amphetamine results in the activation of multiple receptor populations that obviates the regional selectivity of cortical ACh release (Arnold et al., 2000, 2001).

Before outlining the potential functional implications of a regional selectivity in the NAC-based modu- lation of cortical ACh release, the similar effects of NMDA and its antagonist CPP on PFC ACh warrants discussion. The fact that both NMDA and CPP increase ACh release in PFC seems paradoxical, particularly if one assumes that these drugs are acting exclusively on the same glutamate receptor populations in the NAC. While, there is significant overlap in the distribution of NMDA receptors within the NAC that are stimulated or blocked by these two ligands, NMDA and CPP might also influence different targets and, hence, projection pathways. The NMDA receptor is a multimeric complex composed of an NR1 (NR1a-h) and NR2 (NR2A-D) subunit (Laube et al., 1997; Wafford et al., 1995). The NR2 subunits impart the distinct pharmacological and functional properties of the NMDA heterodimer (Buller et al., 1994). NMDA antagonists such as CPP demonstrate their highest affinity toward the NR2A subunit whereas NMDA exhibits its highest affinity for the NR2B subunit (Feng et al., 2005). To the extent that these subunits are present to different degrees on GABAergic interneurons and projection neurons of the NAC, the two NMDA ligands could ultimately affect the BFCS in similar fashion but via different circuits (see Buller et al., 1994; Goebel and Poosch, 1999; Monaghan and Larsen, 1997). For example, by virtue of the distribution of NR2A subunits, CPP might preferentially block NMDA-mediated excitation of NAC GABAergic projections from shell to the magnocellular cholinergic neurons of the basal forebrain. Perfusion of CPP might then render these cholinergic corticopetal neurons more excitable to other local inputs. NR2B subunits might be more heavily distributed on GABAergic interneurons within NAC or on projections from NAC to VTA. Thus, direct stimulation of NMDA receptors might activate a different circuit that still eventuates in the excitation of the prefrontal cortical cholinergic inputs. Importantly, in the present context, these speculations do not limit the significance of the central finding of this study. This finding indicates that NAC manipulations of glutamatergic neurotransmission influence ACh release in the PFC but not PPC.

Finally, the regional selectivity of the NAC modulation of cortical ACh release might well have been biased by the manner in which the rats were tested. In the present experiment and in our previous studies (Neigh-McCandless et al., 2002; Zmarowski et al., 2005), rats were tested while awake and freely moving but, as a result of the extensive habituation to the testing bowls, the animals remained largely at rest during the dialysis session. The question remains whether an NAC-modulated ACh release in PPC would become evident in animals performing in a behavioral task that recruited the BFCS. We have demonstrated that ACh release is increased in both frontoparietal (Himmelheber et al., 2001) and posterior 
parietal cortex (Kozak et al., 2006) during performance of an operant task designed to tax sustained attention. Such data are not surprising given a number of studies revealing a role of parietal cortex in attentional information processing (Broussard et al. 2006; Constantinidis and Steinmetz, 2005; Posner and Petersen, 1990).

The maintenance or recovery of performance levels during presentation of a distractor stimulus necessitates top-down controls in attention (Sarter et al., 2006). We have recently demonstrated that in contrast to cholinergic transmission in PFC, presentation of a distractor does not increase $\mathrm{ACh}$ release in $\mathrm{PPC}$ beyond those already produced by the onset of the sustained attention task (Kozak et al., 2006). However, the distractor did produce an additional increase in $\mathrm{ACh}$ release in $\mathrm{PPC}$ following selective cholinergic lesions of the PFC. We interpret this increase in ACh release as reflecting the neurochemical component of the increased attentional effort required to maintain task performance in the absence of PFC-mediated topdown controls. If cholinergic transmission in PFC is necessary for optimal top-down control of attention, and if changes in NMDA receptor activity within NAC contribute to the activation of these functions of the $\mathrm{PFC}$, then NAC-modulation of $\mathrm{ACh}$ release in $\mathrm{PPC}$ should be evident under conditions that activate such top-down influences. Ongoing studies will test this hypothesis in task-performing animals under conditions of intra-NAC perfusion of NMDA ligands with and without the presentation of visual distractors.

In summary, this experiment demonstrates that NMDA receptor activity in the NAC can trans-synaptically modulate cortical cholinergic transmission. Under resting conditions, this modulation exhibits a clear regional difference-affecting $\mathrm{ACh}$ release in PFC but not in PPC. An NAC-based modulation of prefrontal ACh release may provide the basis for linking motivational factors and attentional processing in the optimization of goal directed behaviors. Future studies will determine whether this regional selectivity of NAC modulation is maintained under conditions that differentially activate the BFCS.

\section{REFERENCES}

Arnold HM, Nelson CL, Neigh GN, Sarter M, Bruno JP. 2000. Systemic and intra-accumbens administration of amphetamine differentially affects cortical acetylcholine release. Neuroscience 96:675-685.

Arnold HM, Fadel J, Sarter M, Bruno JP. 2001. Amphetaminestimulated cortical acetylcholine release: Role of the basal forebrain. Brain Res 894:74-87.

Broussard J, Sarter M, Givens B. Neuronal correlates of signal detection in the posterior parietal cortex of rats performing a sustained attention task. Neuroscience (in press).

Bruno JP, Sarter M, Arnold HM, Himmelheber AM. 1999. In vivo neurochemical markers of cognitive processes: Methodological and conceptual challenges. Rev Neurosci 10:25-49.

Buller AL, Larson HC, Schneider BE, Beaton JA, Morrisett RA, Monaghan DT. 1994. The molecular basis of NMDA receptor subtypes: Native receptor diversity is predicted by subunit composition. J Neurosci 14:5471-5484.
Constantinidis C, Steinmetz MA. 2005. Posterior parietal cortex automatically encodes the location of salient stimuli. J Neurosci 25:233-238.

Corbetta M, Shulman GL. 2002. Control of goal-directed and stimulus-driven attention in the brain. Nat Rev 3:201-215.

Dalley JW, Theobald DE, Bouger P, Chudasama Y, Cardinal RN, Robbins TW. 2004. Cortical cholinergic function and deficits in visual attentional performance in rats following 192 IgG-saporininduced lesions of the medial prefrontal cortex. Cereb Cortex 14:922-932.

Fadel J, Sarter M, Bruno JP. 1999. Age-related attenuation of stimulated cortical acetylcholine release in basal forebrainlesioned rats. Neuroscience 90:793-802.

Feng B, Morely RM, Jane DE, Monaghan DT. 2005. The effect of competitive antagonist chain length on NMDA receptor subunit selectivity. Neuropharmacology 48:354-359.

Fournier GN, Semba K, Rasmusson DD. 2004. Modality- and region-specific acetylcholine release in the rat neocortex. Neuroscience 126:257-262.

Fox MD, Corbetta M, Snyder AZ, Vincent JL, Raichle ME. 2006. Spontaneous neural activity distinguishes human dorsal and ventral attention systems. Proc Natl Acad Sci USA 103:1004610051.

Goebel DJ, Poosch MS. 1999. NMDA receptor subunit gene expression in the rat brain: A quantitative analysis of endogenous mRNA levels or NR1Com, NR2A, NR2B, NR2C, NR2D and NR3A. Brain Res Mol Brain Res 69:164-170.

Greenwald A, Gonzalez R, Harris R, Guthrie D. 1996. Effects sizes and p-values: What should be reported and what should be replicated. Psychophysiology 33:157-183.

Himmelheber AM, Fadel J, Sarter M, Bruno JP. 1998. Effects of local cholinesterase inhibition on acetylcholine release assessed simultaneously in prefrontal and frontoparietal cortex. Neuroscience 86:949-957.

Himmelheber AM, Sarter M, Bruno JP. 2001. The effects of manipulations of attentional demand on cortical aceylcholine release. Brain Res Cogn Brain Res 12:353-370.

Isacson O, Seo H, Lin L, Albeck D, Granholm AC. 2002. Alzheimer's disease and Down's syndrome: Roles of APP, trophic factors and ACh. Trends Neurosci 25:79-84.

Kozak R, Brown H, Bruno JP, Sarter M. 2006. Prefrontal cholinergic modulation of attentional performance-associated increases in posterior parietal acetylcholine release. Soc Neurosci, Abstracts 31:369,15.

Laplante F, Morin Y, Quirion R, Vaucher E. 2005. Acetylcholine release is elicited in the visual cortex, but not in the prefrontal cortex, by patterent visual sitmulation: A dual in vivo microdialysis study with functional correlates in the rat brain. Neuroscience 132:501-510.

Laube B, Hirai H, Sturgess M, Betz H, Kuhse J. 1997. Molecular determinants of agonist discrimination by NMDA receptor subunits: Analysis of the glutamate binding site on the NR2B subunit. Neuron 18:493-503.

Mechawar N, Cozzari C, Descarries L. 2000. Cholinergic innervation in adult rat cerebral cortex: a quantitative immunocytochemical description. J Comp Neurol 482:305-318.

Mirza NR, Stolerman IP. 1998. Nicotine enhances sustained attention in the rat under specific task conditions. Psychopharmacology 138:266-274.

Monaghan DT, Larsen H. 1997. NR1 and NR2 subunit contributions of $N$-methyl-D-aspartate receptor channel blocker pharmacology. J Pharmacol Exp Ther 280:614-620.

Moore H, Sarter M, Bruno JP. 1992. Age-dependent modulation of in vivo cortical acetylcholine release by benzodiazepine receptor ligands. Brain Res 596:7-29.

Moore H, Sarter M, Bruno JP. 1995. Bidirectional modulation of cortical acetylcholine efflux by infusion of benzodiazepine receptor ligands into the basal forebrain. Neurosci Lett 189:31-34.

Moore H, Fadel J, Sarter M, Bruno JP. 1999. Accumbens and cortical dopamine receptor regulation of cortical acetylcholine release. Neuroscience 88:811-822.

Muir JL, Everitt BJ, Robbins TW. 1995. Reversal of visual attentional dysfunction following lesions of the cholinergic basal forebrain by physostigmine and nicotine but not by the 5 -ht3 receptor antagonist, ondansetron. Psychopharmacology 118:82-92.

Neigh GN, Arnold HM, Rabenstein RL, Sarter M, Bruno JP. 2004. Neuronal activity in the nucleus accumbens is necessary for performance-related increases in cortical acetylcholine release. Neuroscience 123:1259-1266.

Neigh-McCandless G, Kravitz BA, Sarter M, Bruno JP. 2002. Ionotropic glutamate receptor blockade in the nucleus accumbens increases cortical acetylcholine release. Eur J Neurosci 16:1259-1266. 
Nelson CL, Sarter M, Bruno JP. 2000. Repeated pretreatment with amphetamine sensitizes increases in cortical acetylcholine release. Psychopharmacology (Berl) 151:406-415.

Nelson CL, Sarter M, Bruno JP. 2005. Prefrontal cortical modulation of acetylcholine release in posterior parietal cortex. Neuroscience 132:347-359.

Pinto A, Sesack SR. 2000. Limited collateralization of neurons in the rat prefrontal cortex that project to the nucleus accumbens. Neuroscience 97:635-642.

Posner MI, Petersen SE. 1990. The attention system of the human brain. Annu Rev Neurosci 13:25-42.

Potter PE, Meek JL, Neff NH. 1983. Acetylcholine and choline in neuronal tissue measured by HPLC with electrochemical detection. J Neurochem 41:188-194.

Reynolds SM, Zahm DS. 2005. Specificity in the projections of prefrontal and insular cortex to ventral striatopallidum and the extended amygdala. J Neurosci 25:11757-11767.

Sarter M, Bruno JP. 1997. Cognitive functions of cortical acetylcholine: Toward a unifying hypothesis. Brain Res Rev 23:2846.

Sarter M, Givens B, Bruno JP. 2001. The cognitive neuroscience of sustained attention: Where top-down meets bottom-up. Brain Res Rev 35:146-160.

Sarter M, Hasselmo ME, Bruno JP, Givens B. 2005a. Unraveling the attentional functions of cortical cholinergic inputs: Interactions between signal-driven and cognitive modulation of signal detection. Brain Res Rev 48:98-111.

Sarter M, Nelson CL, Bruno JP. 2005b. Cortical cholinergic transmission and cortical information processing in schizophrenia. Schizophr Bull 31:117-138.
Sarter M, Gehring WJ, Kozak R. 2006. More attention must be paid: The neurobiology of attentional effort. Brain Res Rev 51: 145-160.

Tandon R, Shipley JE, Greden JF, Mann NA, Eisner WH, Goodson JA. 1991. Muscarinic cholinergic hyperactivity in schizophrenia. Relationship to positive and negative symptoms. Schizophr Res 4:23-30.

Vasey MW, Thayer JF. 1987. The continuing problem of false positives in repeated measures ANOVA in psychophysiology: A multivariate solution. Psychopysiology 24:479-486.

Wafford KA Kathoria M Bain C.J, Marshall G, Lebourdelles B, Kemp JA, Whiting PJ. 1995. Identification of amino-acids in the $N$-methyl-D-aspartate receptor NR1 subunit that contribute to the glycine binding-site. Mol Pharmacol 47:374-380.

Zaborszky L. 2002. The modular organization of brain systems. Basal forebrain: The last frontier. Prog Brain Res 136:359-372.

Zaborszky L, Cullinan WE. 1992. Projections from the nucleus accumbens to cholinergic neurons of the ventral pallidum: A correlated light and electron microscopic double-immunolabeling study in rat. Brain Res 570:92-101.

Zaborszky L, Duque A. 2000. Local synaptic connections of basal forebrain neurons. Behav Brain Res 115:143-158.

Zaborszky L, Pang K, Somogyi J, Nadasdy Z, Kalli I. 1999. The basal forebrain corticopetal system revisited. Ann NYAcad Sci 877: 339-367.

Zaborszky L, Buhl DL, Pobalashingham S, Bjaalie JG, Nadasdy Z. 2005. Three-dimensional chemoarchitecture of the basal forebrain: Spatially specific association of cholinergic and calcium binding protein-containing neurons. Neuroscience 136: 697-713.

Zmarowski A, Sarter M, Bruno JP. 2005. NMDA and dopamine interactions in the nucleus accumbens modulate cortical acetylcholine release. Eur J Neurosci 22:1731-1740. 